\title{
Fighting in pigeons relative to available space
}

FRANK N. WLLIS, JR.

UNIVERSITY OF MISSOURI AT KANSAS CITY

Fighting in pigeons was studied in relation to available space in cages of four sizes. Behavioral measures consisted of frequency of fighting response, response latency, and time of final fighting response. In general, fighting was found to increase with a decrease in available space although the visual properties of the space appeared to be important in determining the frequency of fighting and response latency. Other factors such as age and prefighting behavioral patterns also appeared to contribute to the frequency of fighting.

A great deal has been written about territorial fighting in many species of birds (e.g. Tinbergen, 1953, 1954). Fighting in pigeons has received little attention. Territorial fighting in pigeons who maintain permanent nesting sites may differ from that of the seasonal breeders previously studied. Territoriality as used here will refer to an observable division of space that cannot be entered without attack by the occupant.

Fighting in pigeons has been described as a highly stereotyped pattern of behavior by Levi (1957), and by Reynolds et al (1963). Reynolds et al found that this pattern could be conditioned, but once initiated continued independent of the reinforcer.

In addition to observational studies of territorial fighting, a few well controlled studies have been reported in which fighting was related to specific dimensions of available space. Ulrich \& Azrin (1962) found that pain elicited fighting in rats occurred on $90 \%$ of trials with a 6 in. $x 6$ in. floor space but on only $2 \%$ with a 24 in. $x 24$ in. floor space. Clark (1962) reported that fighting in mice increased with confinement in a small space. He reasoned that the sudden dis ruption of customary territoriality resulted in increased excitability and an accompanying increase in aggression. Marler (1956) observed that fighting in Chaffinches increased in probability with smaller distance between birds at a feeding station.

The purpose of the present study was to investigate the relationship between fighting pigeons and available space. It was hypothesized that fighting would increase as available space decreased and that fighting would cease sooner in spaces large enough to permit the establishment of territory.

\section{Subjects}

Seven Modenas and one Racing Homer were used as Ss. All were experimentally naive males. The birds had mates and were housed in a common loft. Six had 1964 seamless bands, one had a 1959 band, and one had a 1957 band. They ranged in weight from 391 to $521 \mathrm{gm}$ when the study was begun. All birds were on ad lib food and water.

\section{Apparatus}

Fighting was observed in four cages. Cage A was 28 in. wide, 34 in. long, and 29 in. high. Cage B was 24 in. wide, 29 in. long, and 21 in. high. Cage $C$ was 20 in. wide, 24 in. long, and 12 in. high. Cage D was $16 \mathrm{in}$. wide, $16 \mathrm{in.} \mathrm{long}$, and $9 \mathrm{in}$. high. Cages A, C, and $D$ were commercial animal cages with a combination of solid panel and grillwork sides. Cage B was made for this study in order to obtain a size midway between $A$ and $C$. Response time was recorded with a stopwatch. Procedure

A round robin tournament was used, each bird paired with every other bird. The resulting 28 combinations were paired for two sessions in each of the four cages yielding a total of 224 sessions. No pair of birds was run on consecutive sessions, otherwise order was randomized. Sessions were $5 \mathrm{~min}$. in length. Birds were returned to the home loft after $5 \mathrm{~min}$. whether or not fighting occurred. Pecking and wing slaps were recorded as fighting. A judge recorded the number of fighting responses for each bird after each 5 sec. interval. Preliminary observations on other birds indicated a high degree of inter-judge reliability. Male pigeons are extremely quiet during their incubation period from 10 a.m. to 3 p.m. so no sessions were run during this period.

Results

The data made possible an analysis of the number of fighting responses, response latency, and time of the last fighting response. The total fighting responses for all sessions were 173 in A, 82 in B, 468 in $C$, and 1473 in $D$. A high frequency of sessions in which no fighting occurred resulted in a skewed distribution that was not appropriate for a parameter analysis. A Friedman two-way analysis of variance by ranks of the 28 pairs in four cages yielded a $\mathrm{x}_{\mathrm{r}}^{2}$ of 16.6 with $\mathrm{df}=3$, and $\mathrm{p}<.001$.

A second analysis of the data was made of the frequency of sessions in which fighting occurred for the four cages. The frequencies are as follows: A-fighting in 27 of 56 sessions, B-in 18 of $56, C-42$ of 56 , and $D-50$ of 56 . A chi-square analysis yielded a $X^{2}=46.96$ with $\mathrm{df}=3$, and $\mathrm{p}<.001$.

Response Latency. The median times for the first fighting response (in sessions where fighting occurred) were as follows: A 30 sec., B 45 sec., C 20 sec., and D 15 sec. A chi-square analysis with three time divisions by four cages resulted in a $X^{2}=19.33$ with $\mathrm{df}=6$, and $\mathrm{p}<.01$.

Time of Final Fighting Response. The median times for the final fighting response for the four cages were: 
A 60 sec., B 67.5 sec., C 150 sec., and D $267.5 \mathrm{sec}$. A chi-square analysis with three time divisions by four cages yielded a $x^{2}=7.32$ with $d f=6$, and $p<.01$.

Other Factors Related to Fighting. In addition to available space other factors were observed for possible relationships to fighting. They were: size, dominance in the home loft, age, and pre-fight behavior patterns.

We might guess that the size of an animal would contribute to his ability as a fighter, but there is no support for this guess in this data. A rank order correlation between weight and number of fighting responses resulted in an $r_{S}=-.19$. When dominance was defined in terms of greater frequency of fighting responses for a particular session, a rank order correlation between weight and frequency of session dominance yielded an $r_{\mathrm{S}}=-.39$. The largest animal was observed by number of independent observers to dominate fighting in the home loft in neutral areas. In this study he ranked sixth in total fighting responses, sixth in frequency of session dominance, and had the highest number of sessions in which he did not fight.

Two of the birds were considerably older than the others. When these birds were paired fighting occurred least often, in only two of eight sessions. They had the lowest total of fighting responses, nine as compared to the high of 217. One of these birds was an opponent in the pair with the highest total. Apparently older birds tend not to fight with each other although they do fight frequently with younger birds.

Coaxing or strutting is one of the most frequent behavior patterns for male pigeons in a home loft. A detailed description of this pattern may be found in Levi (1957). When coaxing occurs in the presence of a receptive female, she initiates billing which is followed by copulation. In new situations or in similar situations with new birds, coaxing often occurs regardless of the sex of the other birds. When the other bird turns out to be a male, the coaxing male usually receives a peck for his performance. In the experimental sessions coaxing often occurred even though the birds had been housed together for months prior to the beginning of the study. In 137 sessions in which coaxing occurred fighting followed in 78. In 87 sessions in which coaxing did not occur fighting occurred only 23 times. A chi-square analysis of this data yielded a $\mathrm{X}^{2}=19.98$ with $\mathrm{df}=1$ and $\mathrm{p}<.001$. Fighting was considerably more probable when coaxing first appeared.

\section{Discussion}

In this study a decrease in available space was accompanied by higher rates of fighting in pigeons as it did in studies with rats, mice, and chaffinches. This generalization was most clearly supported by the data on the final fighting response. In the largest cage territories were established and fighting tended to cease at an earlier time. The bird who was dominated remained quiet in a particular corner of the cage while the dominant bird paced throughout most of the space.

Results based upon number of attacks and response latency did not provide unqualified support for the generalization relating fighting and space. Attacks were least frequent and latencies longest not in the largest cage, but in the next size smaller. This cage (B) differed from the others in that the surrounding areas of the lab were much more visible from the cage. When placed in this cage birds tended to walk around looking outside the cage rather than at each other. It would appear that a meaningful generalization concerning fighting and space should specify the visual properties of the space.

Factors other than the properties of the space appear to effect fighting in a restricted space. There was some evidence that the age of the birds and the patterns of behavior prior to fighting were important. On the other hand, size which was mentioned as important in the fighting of mice by Clark (1962) was not found to be related to fighting in pigeons.

Finally generalizations based upon studies such as the present one may have application only to situations new to the animals since the relative rate of fighting for the birds in this study was quite different from that in the home loft.

\section{References}

Clark, L. D. Experimental studies of the behavior of an aggressive predatory mouse. In E. L. Bliss (Ed.), Roots of behavior. New York: Harper, 1962. Pp. 179-186.

Levi, W. The pigeon. Columbia, S. C.: Bryan, 1957.

Marler, P. Studies of fighting in Chaffinches (3) Proximity as a cause of aggression. Brit. J. Anim. Behav., 1956, 4, 23-30.

Reynolds, G. S., Catania, A. C., Skinner, B. F. Conditioned and unconditioned aggression in pigeons. $J$, exp. Anal. Behav. $1963,6,73-64$.

Tinbergen, N. Social behavior in animals. London: Methan, 1953. Tinbergen, N. Bird life. London: Oxford U. Press, 1954.

Siegel, S. Nonparametric statistics for the behavioral sciences. New York: McGraw-Hill, 1956.

Ulrich, R. E., \& Azrin, N. H. Reflexive fighting in response to aversive stimulation. J. exp. Anal. Behav., 1962, 5, 511-520. 